\title{
Palliative care referral criteria and outcomes in cancer and heart failure: a systematic review of literature
}

\author{
Anecita P. Fadol ${ }^{1,2^{*}}$ (D, Ashley Patel ${ }^{3}$, Valerie Shelton ${ }^{1}$, Kate J. Krause ${ }^{4}$, Eduardo Bruera ${ }^{5}$ and Nicolas L. Palaskas ${ }^{2}$
}

\begin{abstract}
Background: Cardiotoxicity resulting in heart failure (HF) is among the most dreaded complications of cancer therapy and can significantly impact morbidity and mortality. Leading professional societies in cardiology and oncology recommend improved access to hospice and palliative care (PC) for patients with cancer and advanced HF. However, there is a paucity of published literature on the use of PC in cardio-oncology, particularly in patients with $\mathrm{HF}$ and a concurrent diagnosis of cancer.
\end{abstract}

Aims: To identify existing criteria for referral to and early integration of PC in the management of cases of patients with cancer and patients with $\mathrm{HF}$, and to identify assessments of outcomes of PC intervention that overlap between patients with cancer and patients with HF.

Design: Systematic literature review on PC in patients with HF and in patients with cancer.

Data sources: Databases including Ovid Medline, Ovid Embase, Cochrane Library, and Web of Science from January 2009 to September 2020.

Results: Sixteen studies of PC in cancer and 14 studies of PC in HF were identified after screening of the 8647 retrieved citations. Cancer and HF share similarities in their patient-reported symptoms, quality of life, symptom burden, social support needs, readmission rates, and mortality.

Conclusion: The literature supports the integration of PC into oncology and cardiology practices, which has shown significant benefit to patients, caregivers, and the healthcare system alike. Incorporating PC in cardio-oncology, particularly in the management of HF in patients with cancer, as early as at diagnosis, will enable patients, family members, and healthcare professionals to make informed decisions about various treatments and end-of-life care and provide an opportunity for patients to participate in the decisions about how they will spend their final days.

Keywords: Palliative care, Supportive care, cancer, Heart failure, Referral criteria, Outcomes

\footnotetext{
* Correspondence: afadol@mdanderson.org

'Department of Nursing, The University of Texas MD Anderson Cancer Center, Houston, TX, USA

${ }^{2}$ Department of Cardiology, The University of Texas MD Anderson Cancer Center, Houston, TX, USA

Full list of author information is available at the end of the article
}

(C) The Author(s). 2021 Open Access This article is licensed under a Creative Commons Attribution 4.0 International License, which permits use, sharing, adaptation, distribution and reproduction in any medium or format, as long as you give appropriate credit to the original author(s) and the source, provide a link to the Creative Commons licence, and indicate if changes were made. The images or other third party material in this article are included in the article's Creative Commons licence, unless indicated otherwise in a credit line to the material. If material is not included in the article's Creative Commons licence and your intended use is not permitted by statutory regulation or exceeds the permitted use, you will need to obtain permission directly from the copyright holder. To view a copy of this licence, visit http://creativecommons.org/licenses/by/4.0/ The Creative Commons Public Domain Dedication waiver (http://creativecommons.org/publicdomain/zero/1.0/) applies to the data made available in this article, unless otherwise stated in a credit line to the data. 


\section{Introduction}

Cancer and heart disease are the leading causes of death in the United States [1]. The intersection of both is addressed by a new multidisciplinary specialty known as cardio-oncology, which focuses on cardiovascular care in patients with cancer. Among the most dreaded complications of cancer therapy is heart failure (HF), which can occur acutely during the therapy or arise several years after completion of the therapy. The burden of disease and its associated impact on the patient and caregiver in cancer and HF are exceedingly high and compounded when both diseases coexist. An interdisciplinary palliative care (PC) intervention can improve the patient's quality of life, while minimizing caregiver distress and aggressive measures at the end of life. The World Health Organization (WHO) defines PC as "an approach that improves the quality of life of patients and their families, facing the problem associated with life threatening illness, through the prevention and relief of suffering by means of early identification and impeccable assessment and treatment of pain and other problems, physical, psychosocial and spiritual." The WHO recommends that PC should be available to everyone suffering from lifethreatening diseases and should be started early in the illness trajectory [2].

In oncology patients, one of the key barriers to early $\mathrm{PC}$ referral is the misunderstanding that $\mathrm{PC}$ is only provided at the end of life once patients have exhausted all cancer treatment options. Oftentimes, PC is misinterpreted for hospice or end of life care. Therefore, it is crucial to differentiate between PC and hospice care. Hospice is comfort care without curative intent and is used when the patient no longer has curative options or attempts to cure the person's illness are stopped and the individual is approaching the end of life [3]. Whereas in $\mathrm{PC}$, patients may receive medical care for their symptoms, along with treatment intended to cure their serious illness. PC is meant to enhance a person's current care by focusing on quality of life for them and their family.

The traditional model of PC is a system of care delivery most appropriate for patients with a predictable trajectory of illness and death, such as that of terminal cancer. Similar to cancer, the advancement of HF into later stages also follows known patterns as symptoms become more intense and refractory to standard treatments, leading to recurrent acute-care utilization and contributing to poor quality of life [4]. However, the symptom burden and HF classification, such as the New York Heart Association (NYHA) classification [5], are dependent on a patient's fluid overload status and can wax and wane unpredictably. Regardless, the symptom burden in HF, including dyspnea, pain, anxiety, fatigue, and depression, can equal or exceed that in cancer populations [6]. Yet, evidence shows that HF patients have suboptimal access to and provision of $\mathrm{PC}$ and hospice [7-11].

In 2015, the National Academy of Medicine (formerly called the Institute of Medicine) issued recommendations to improve advance care planning and increase access to PC for all seriously ill patients [12, 13]. Subsequently, leading professional societies including the American College of Cardiology, American Heart Association, Heart Failure Society of America, and the International Society for Heart and Lung Transplantation published clinical guidelines recommending improved access to hospice and PC for patients with advanced HF [14-20]. Likewise, the American Society of Clinical Oncology, the National Comprehensive Cancer Network (NCCN), and the National Academy of Medicine have endorsed timely PC referral for cancer patients [21-23]. However, despite guidelines recommending the inclusion of $\mathrm{PC}$, there are limited data offering guidance on $\mathrm{PC}$ in patients with a dual diagnosis of cancer and HF. Therefore, we conducted this systematic literature review with the following aims:

(1) To identify existing criteria for referral to and early integration of $\mathrm{PC}$ in the management strategies for patients with cancer and patients with HF.

(2) To identify assessments of outcomes of PC intervention that overlap between patients with cancer and patients with HF.

This review will provide baseline information to define best practices for referral to and successful delivery of PC to patients living with cancer and HF.

\section{Methods \\ Study design and search strategy}

We performed a systematic search of the literature for studies assessing criteria for and outcomes of PC referral in both HF and cancer. We searched Ovid Medline, Ovid Embase, Cochrane Library, and Web of Science from January 2009 to September 2020. Search structures, subject headings, and keywords were tailored to each database by a medical research librarian (KJK) specializing in systematic reviews. Case reports, animal studies, and articles in languages other than English were excluded, without any other restrictions by study type. Search strings included $\mathrm{MeSH}$ and Emtree subject headings, which included: "heart failure", "neoplasms", "hospice care", and "palliative care". Keyword searching was used to retrieve articles with related terms and phrases in the titles and abstracts. 


\section{Study selection}

Our initial search retrieved 8,647 citations, and after removal of duplicates, 5,482 citations remained for review, comprising 4,180 articles for cancer and 1,302 articles for HF. Citations were independently screened by two investigators (APF, AP) by using the titles and abstracts of the articles to identify potentially relevant studies. Disagreements were resolved by consensus and by seeking the opinion of a third reviewer (NLP). Studies that passed the title/ abstract review were retrieved for full-text review. The two screening investigators (APF, NLP) then independently screened the remaining full-text articles. Disagreements were resolved by consensus and by seeking the opinion of a third reviewer (EB). After final review, 16 studies on cancer and 14 studies on HF were included. A PRISMA flow diagram (Figure 1) shows the entire review process from the original search to the final selection of studies.

\section{Statistical methods}

The main outcome measures for this systematic literature review were criteria for and outcomes of referral to PC for patients with diagnoses of cancer and HF. Because of the heterogeneity of study designs, participants, interventions, and reported outcomes, meta-analytical statistical comparison was not possible. Therefore, we focused on describing the studies, their results, and their limitations via a qualitative synthesis.

\section{Results}

The studies selected for inclusion in the review were analyzed for risk of bias to understand and appraise their strengths and weaknesses, and results are outlined in Table 1 (cancer) and Table 2 (heart failure).

\section{Cancer}

Of the 16 studies included in the systematic review regarding cancer and $\mathrm{PC}$, nine studies looked at referral criteria, and six studies evaluated referral outcomes. Five studies were prospective [24-28], four were retrospective [29-32], five were cross-sectional surveys [33-37], and two randomized controlled trials $[28,38]$ (Table 3$)$.

\section{Referral criteria}

Four studies [26, 30, 33, 34] identified and characterized the PC needs of cancer patients using questionnaires and assessment instruments. Sanders et al. (2010) reported that patients' greatest PC needs were in the physical and daily living domain, followed by psychological needs, health system and informational needs, and patient care support needs. The most common unmet need was a lack of energy and tiredness (75\%). Grudzen et al. (2010) used the validated assessment instruments Needs at the Endof-Life Screening Tool (NEST) [39], McGill Quality of Life Questionnaire (MQOL) [40], and Edmonton Symptom Assessment System (ESAS) [41] to assess (1) the range and severity of symptoms, (2) goals of care, (3) psychological well-being, (4) health care utilization, (5) spirituality, (6) social connectedness, (7) financial burden, (8) the patient-clinician relationship, and (9) overall quality of life. Results showed that in all nine of the above categories, more than $50 \%$ of patients suffered not just from physical symptoms (47/50, 94\%), but also from mental distress $(31 / 50,62 \%)$, financial hardship (36/50, 72\%), mental health (31/50, $62 \%$, and difficulty accessing care (29/50, 58\%). The majority of patients reported moderate to severe fatigue, pain, dyspnea, and depression on the ESAS [41]. Caraceni et al. (2020) used multidimensional systematic symptom assessment to determine referral to $\mathrm{PC}$, hospice, or home care when needed. Patients with the highest symptom burden were more likely to be referred earlier, and $75 \%$ of them died within 1 year from referral. Among symptoms, frequent reasons for referral included pain, respiratory symptoms, asthenia, and loss of appetite. Other clinical conditions associated with referral were deterioration of performance status and presence of brain metastases.

Molin et al. (2019) explored the use of the PALLIA-10 questionnaire for referral of advanced cancer patients to a dedicated PC team. PALLIA10 is a multidimensional 10 -item screening form addressing medical, psycho-social, and ethical issues with scoring from 0 to 10 to categorize patients by their PC requirement. Results showed that patients were significantly more frequently referred to a PC team when their PALLIA-10 score was $>3$ (adjusted odds ratio, 2.6; 95\% CI, 1.65-4.11). PALLIA-10 score appeared to be a reliable and prognostic instrument for identifying patients for PC referral.

To facilitate PC referral, a panel of 60 international palliative care experts developed a list of criteria for referral of patients with advanced cancer for 


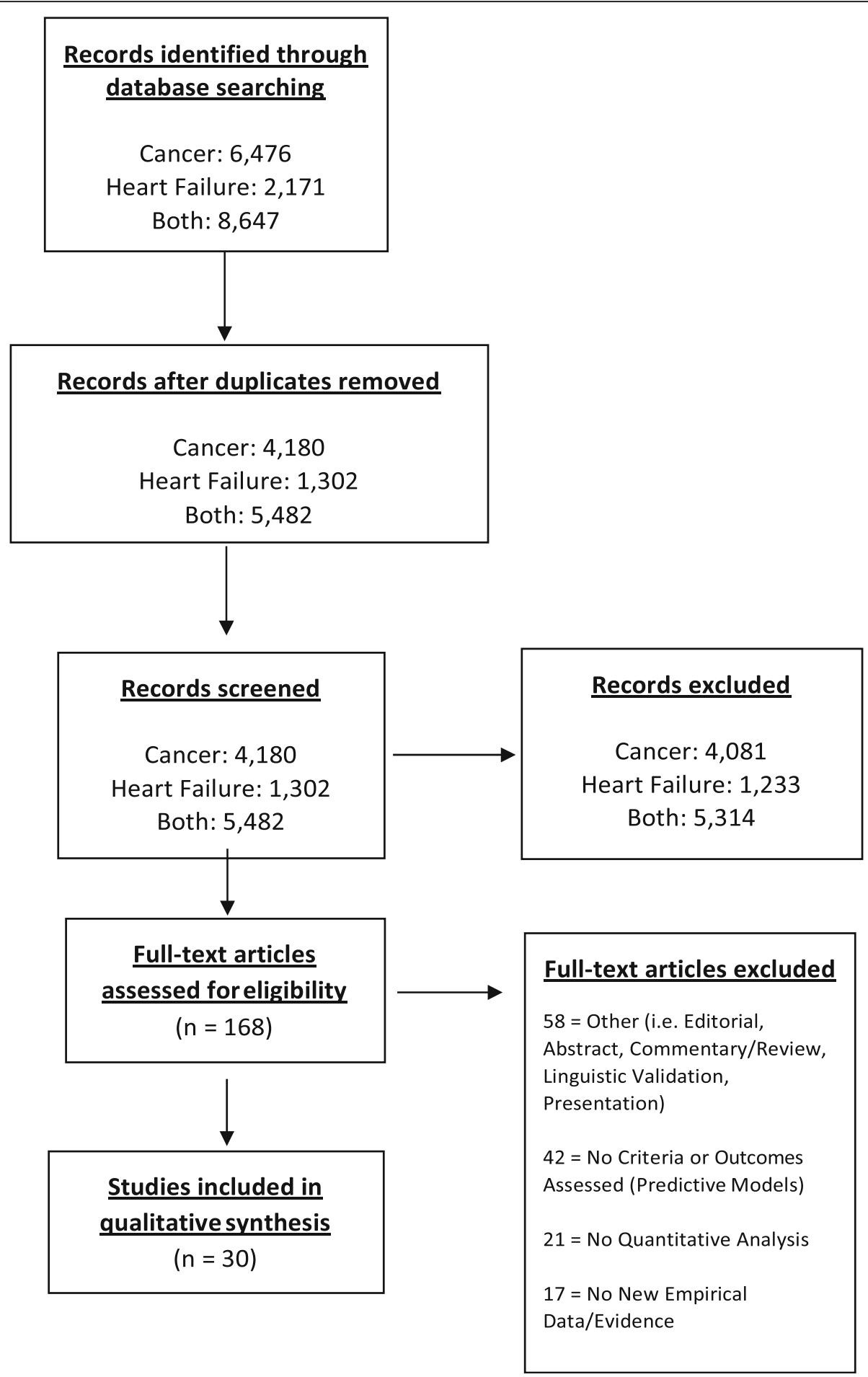

Fig. 1 PRISMA diagram

outpatient palliative care [42]. Using the Delphi study methodology, the panelists rated 39 needsbased criteria and 22 time-based criteria. Of those, they reached consensus on 11 major criteria for referral which includes: severe physical symptoms, severe emotional symptoms, request for hastened death, spiritual or existential crisis, assistance with decision making or care planning, patient request for referral, delirium, spinal cord compression, brain or leptomeningeal metastases, 


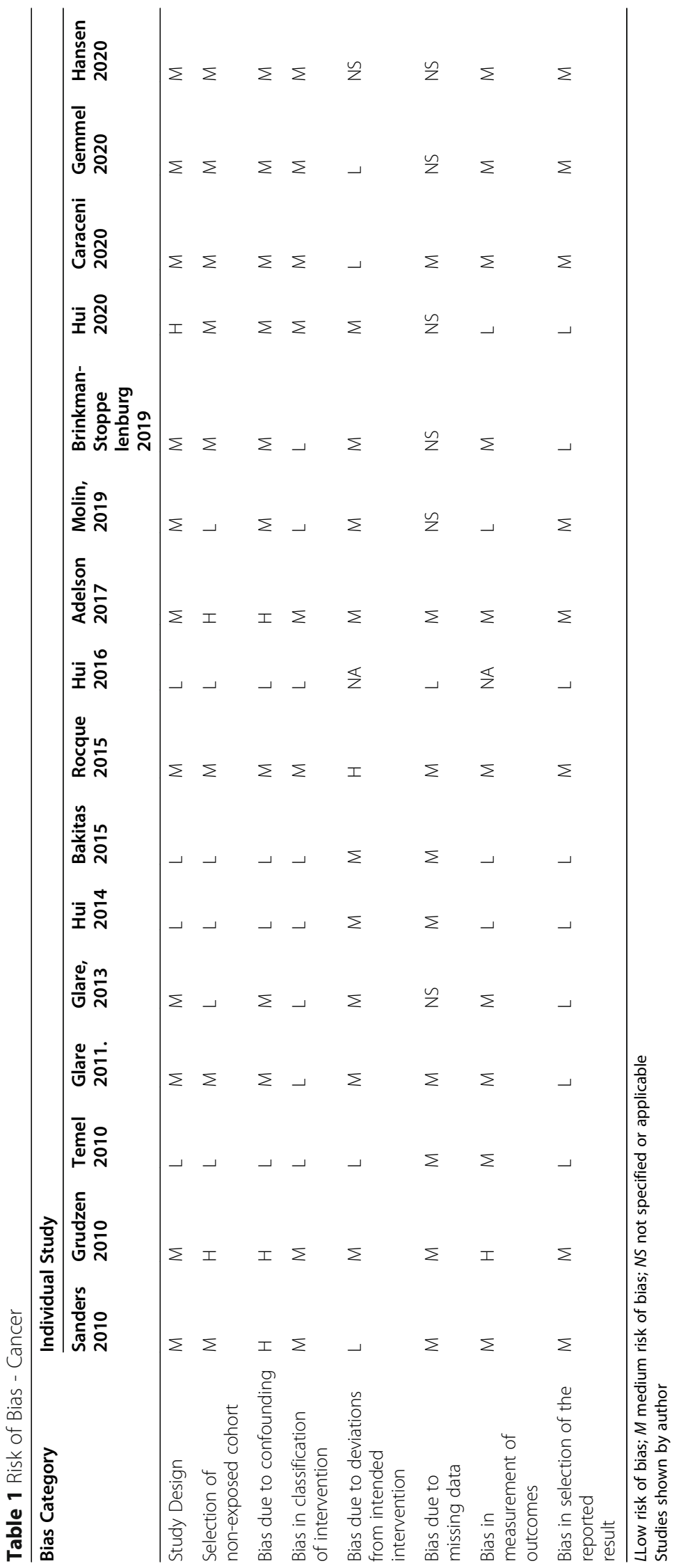




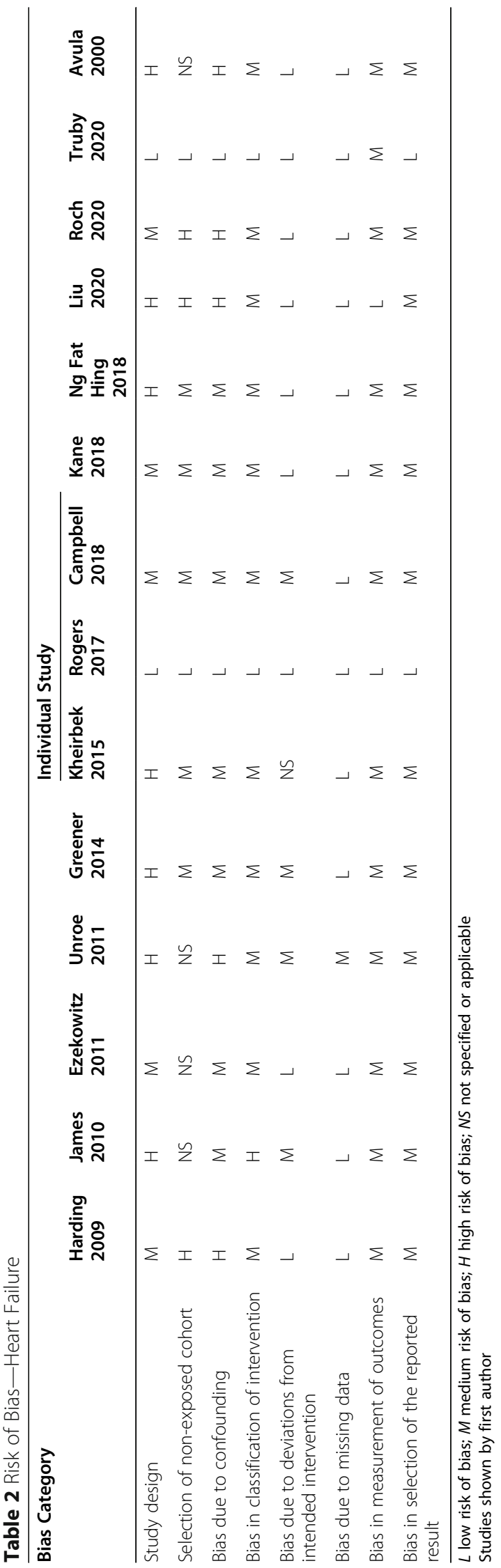


Table 3 Palliative/Supportive Care in Cancer Patients

Grudzen et al. 50 seriously ill adults 2010. with co- existing cancer department

Temel et al. 2010

151 patients with metastatic lung cancer

To examine the effect of early palliative care integrated with standard oncologic care on patientreported outcomes, the use of health services, and the quality of end-of-life care among patients with metastatic non-small-cell lung cancer. of seriously ill, older adults in the

\begin{tabular}{lll}
\hline Study & Population & Aims \\
\hline $\begin{array}{l}\text { Sanders, et al. } \\
\text { 2010. }\end{array}$ & $\begin{array}{l}\text { cancer } \\
\text { contients with lung }\end{array}$ & $\begin{array}{l}\text { To characterize the prevalence and } \\
\text { intensity of supportive care needs } \\
\text { and interest in specific supportive } \\
\text { care services among individuals with } \\
\text { lung cancer }\end{array}$
\end{tabular}
in the emergency

\section{Design}

Cross-sectional survey

To identify the palliative care needs emergency department (ED).
Cross-sectional survey

Non-blinded, randomized, controlled trial

and

\section{Key Findings}

Participants reported the greatest need in the physical and daily living domain, followed by psychological needs, health system and informational needs, and patient care support needs. The most common unmet need was a lack of energy and tiredness (75\%). Higher levels of supportive care needs were associated with worse physical functioning, greater symptom bother, lower satisfaction with health care, and

higher levels of intrusive thoughts about cancer.

Over half of the patients exceeded intratest severity-of- needs cutoffs in four categories of the Needs Near End of Life (NEST): physical symptoms (47 / 50, 94\%),

finances ( $36 / 50,72 \%)$, mental health $(31 / 50,62 \%)$, and access to care $(29 / 50,58 \%)$. The majority of patients reported moderate to severe fatigue, pain,

dyspnea, and depression on the ESAS.

Patients assigned to early palliative care had a better quality of life than did patients assigned to standard care (mean score on the FACT-L scale, in which scores range from 0 to 136 , with higher scores indicating better quality of life], 98.0 vs. $91.5 ; P=0.03$ ). In addition, fewer patients in the palliative care group than in the standard care group had depressive symptoms ( $16 \%$ vs. $38 \%, P=0.01$ ). Despite the fact that fewer patients in the early palliative care group than in the standard care group received aggressive end-of-life care (33\% vs. $54 \%, P=0.05)$, median survival was longer among patients receiving early palliative care

(11.6 months vs. 8.9 months, $\mathrm{P}=0.02$ ).

To explore the implementation of the Cross-sectional survey NCCN screening and referral criteria

119 patients in a oncology practice specializing in colorectal cancer and neuroendocrine tumors

Glare, et al. 2013

194 gastrointestinal oncology patients

To evaluate the feasibility and impact

of implementing the NCCN

Guidelines referral criteria as a trigger for PC

consults

Hui et al. 2014366 cancer patients with $P C$ referral and quality of care indicators

To examine how the timing and setting of PC referral were associated with the quality of end-of-life care
Cross-sectional survey

Using the 24 items for NCCN referral criteria to screen for specialist palliative care provider, identified 7 to $17 \%$ of patients as having PC issues and $13 \%$ of patients who might benefit from specialist referral.

Using the NCCN guidelines as a referral trigger, patients had a significant increase in access to the PC service, and appeared to occur earlier in the course of the disease. Almost two-thirds (73\%) of patients would meet the criteria for a PC consult.

Earlier PC referral was associated with fewer emergency room visits (39\% vs 68\%; $\mathrm{P}<.001$ ), fewer hospitalizations (48\% vs $81 \% ; P<.003)$, and fewer hospital deaths ( $17 \%$ vs $31 \%$; $P=$ 
Table 3 Palliative/Supportive Care in Cancer Patients (Continued)

.004) in the last 30 days of life. Similarly, outpatient PC referral was associated with fewer emergency room visits ( $48 \%$ vs $68 \%$; $P<.001$ ), fewer hospital admissions (52\% vs $86 \%$; $P<.001)$, fewer hospital deaths (18\% vs 34\%; P5.001), and fewer intensive care unit admissions (4\% vs 14\%; P5.001). In multivariate analysis, outpatient PC referral (odds ratio [OR], $0.42 ; 95 \%$ confidence interval $[\mathrm{Cl}$, $0.28-0.66 ; \mathrm{P}<.001$ )

was independently associated with less aggressive end-of-life care. Men (OR, 1.63; 95\% Cl, 1.06-

2.50; P5.03) and hematologic malignancies (OR, 2.57; $95 \%$ Cl, 1.18 5.59 ; P5.02) were associated with more aggressive end-of-life care.

Bakitas et al. 207 patients with 2015 advanced cancer

Rocque et al. 203 patients with 2015 hematologic malignancies
To compare the effect of early versus delayed PC on quality of life (QOL) symptom impact, mood, 1- year survival, and resource use.
Randomized controlled trial

Patient-reported outcomes and resource use were not statistically significant between early versus delayed referral to palliative care. However, the 1-year survival rates after enrollment was improved with those in the early group (63\%) compared to $48 \%$ in the

delayed group (difference, 15\%; P $=.038$ ). Relative rates of early to delayed decedents' resource use were similar for hospital days, intensive care unit days, emergency room visits, chemotherapy in last 14 days, and home death.

To evaluate the implementation of triggered palliative care consultation (TPCC) as part of standard care
Prospective, pre-post, sequential cohort study

Implementation of TPPC significantly improved patients' prognostic awareness of their cancer from 65 to $94 \%$, enhanced the communication between the patient, PC provider and was viewed favorably by $74 \%$ of the oncologists. TPCC had minimal impact on hospice utilization, cost of care, survival, patient reported symptoms, and patient satisfaction, likely because

of the limited nature of the intervention.

Hui et al. 201660 international experts on palliative care

To develop consensus on a list of criteria for referral of patients with advanced cancer at secondary or tertiary care hospitals to outpatient palliative care
Delphi method using a structured communication technique to establish a convergence of opinion.
Panelists reached consensus on 11 major and 36 minor criteria for referral to palliative care (11 major criteria: severe physical symptoms, severe emotional symptoms, request for hastened death, spiritual or existential crisis, assistance with decision making or care planning, patient request for referral, delirium, spinal cord compression, brain or leptomeningeal metastases, within 3 months of advanced cancer diagnosis for patients with median survival of 1 year or less, and progressive disease despite second-line therapy. Consensus was also reached on 36 minor criteria for specialist palliative- care referral. 
Table 3 Palliative/Supportive Care in Cancer Patients (Continued)

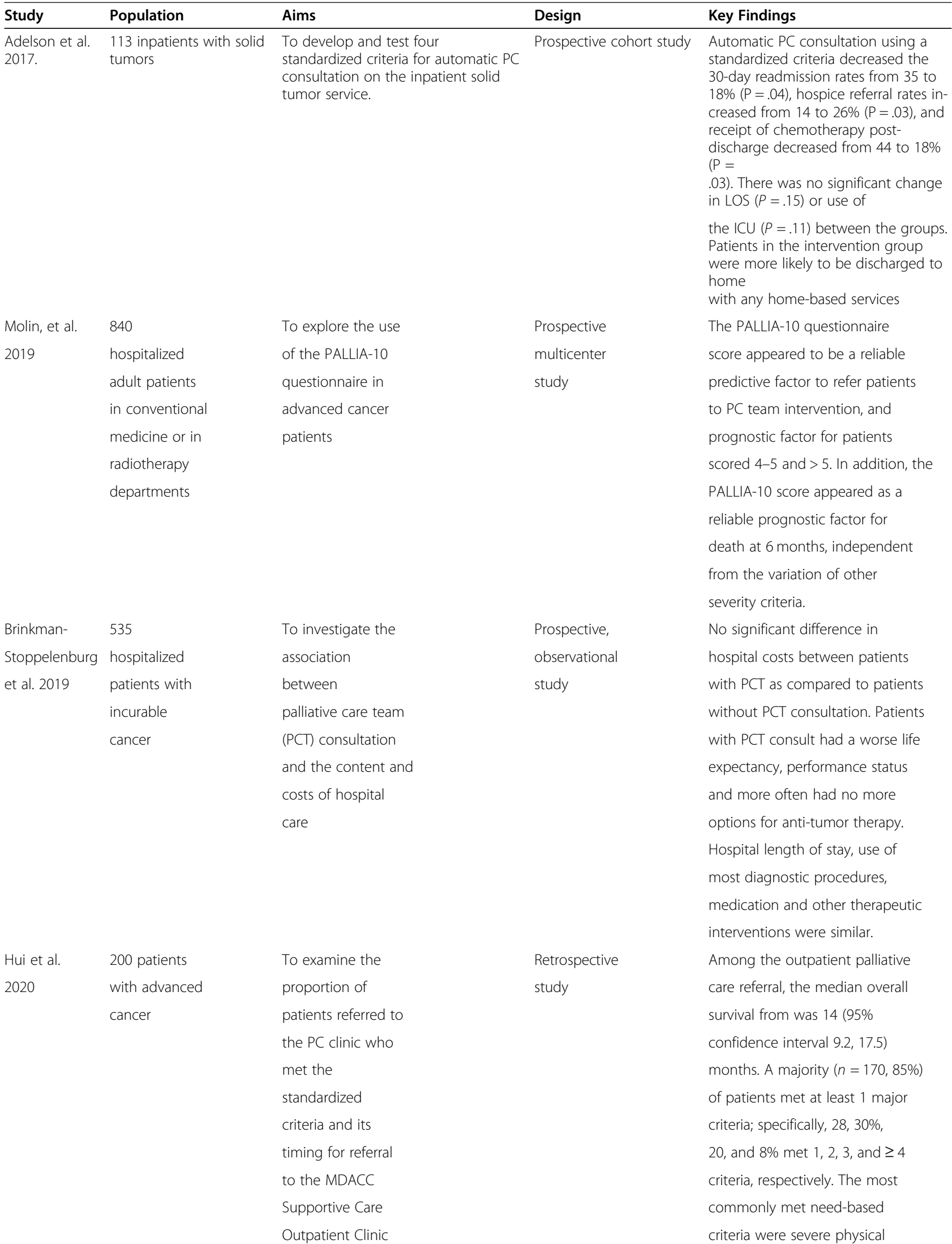


Table 3 Palliative/Supportive Care in Cancer Patients (Continued)

\begin{tabular}{|c|c|c|c|c|}
\hline Study & Population & Aims & Design & Key Findings \\
\hline & & & & symptoms ( $n=140,70 \%)$, \\
\hline & & & & emotional symptoms ( $n=36$, \\
\hline & & & & $18 \%$ ), decision-making needs $(n=$ \\
\hline & & & & $26,13 \%)$, and \\
\hline & & & & brain/leptomeningeal metastases \\
\hline & & & & $(n=25,13 \%)$. For time-based \\
\hline & & & & criteria, 54 (27\%) were referred \\
\hline & & & & within 3 months of diagnosis of \\
\hline & & & & advanced cancer and 63 (32\%) \\
\hline & & & & after progression from $\geq 2$ lines of \\
\hline & & & & palliative systemic therapy. The \\
\hline & & & & median duration from patient first \\
\hline & & & & meeting any criterion to palliative \\
\hline & & & & $\begin{array}{l}\text { care referral was } 2.4 \text { (interquartile } \\
\text { range } 0.1,8.6 \text { ) months }\end{array}$ \\
\hline \multirow{17}{*}{$\begin{array}{l}\text { Caraceni, A. et } \\
\text { al. (2020) }\end{array}$} & 229 patients & To identify timing & Observational & Referral to Palliative care \\
\hline & with thoracic & and factors & retrospective & Outpatient Clinic (POC) was \\
\hline & malignancies & associated to PC & study & significantly higher for patients \\
\hline & & referral in patients & & with worse performance status \\
\hline & & with thoracic & & (PS) $(H R=4.5)$, more advanced \\
\hline & & malignancies, and & & disease stage $(H R=3.1)$, pain \\
\hline & & to describe their & & $(H R=4.9)$, dyspnea $(H R=2.5)$ and \\
\hline & & clinical care & & cough \\
\hline & & pathway. & & $(H R=2.2)$. The multivariable model \\
\hline & & & & confirmed independent \\
\hline & & & & prognostic value for PS, disease \\
\hline & & & & stage and pain. Results suggest \\
\hline & & & & considering symptom burden, PS \\
\hline & & & & and disease stage as screening \\
\hline & & & & criteria for referral to $P C$ in \\
\hline & & & & patients with thoracic \\
\hline & & & & malignancies. \\
\hline \multirow{12}{*}{$\begin{array}{l}\text { Gemmel, R. et } \\
\text { al } \\
\text { (2020) }\end{array}$} & 159 patients & To identify the & Retrospective & Of the 159 patients identified, 46 \\
\hline & who died & prevalence of & cohort study & $\%$ were referred to palliative care \\
\hline & during hospital & cancer & & prior to terminal admission. \\
\hline & admission, who & patients who died & & Application of 6 out of 7 trigger \\
\hline & met criteria for & during a non- & & tools would have resulted in the \\
\hline & palliative care & elective hospital & & majority of patients (up to $91.2 \%$ ) \\
\hline & consultation & admission, who met & & referred to palliative care prior to \\
\hline & & the criteria for a & & admission. Most patients (52.2\%) \\
\hline & & palliative care & & were referred only during their \\
\hline & & consultation within & & terminal admission. Patients \\
\hline & & the 6 months prior & & known to palliative care before \\
\hline & & to death according & & admission $(N=73)$ were reviewed \\
\hline
\end{tabular}


Table 3 Palliative/Supportive Care in Cancer Patients (Continued)

\begin{tabular}{|c|c|c|c|c|}
\hline Study & Population & Aims & Design & Key Findings \\
\hline & & to a number of & & quicker than those who were not \\
\hline & & palliative care & & $(N=86)$ (median (range) 1 day $(0-23$ \\
\hline & & referral trigger & & days) versus 5 days ( $0-59$ days), \\
\hline & & tools. & & $p<0.00001)$ \\
\hline \multirow{18}{*}{$\begin{array}{l}\text { Hansen, MB et } \\
\text { al (2020) }\end{array}$} & 31,139 adult & To investigate if the & Retrospective & Clinically neglectable associations \\
\hline & cancer patients & symptomatology & review & were found between patients \\
\hline & registered in & (EORTC QLQ-C15- & & referred by the general \\
\hline & the Danish & PAL questionnaire) & & practitioner and hospital \\
\hline & Palliative Care & differed for patients & & physician related to symptoms \\
\hline & database & referred to & & (pain, appetite loss, fatigue), \\
\hline & & specialized palliative & & number of symptoms/problems, \\
\hline & & care from general & & number of severe symptoms/ \\
\hline & & practitioners in the & & problems (odds ratios between \\
\hline & & primary healthcare & & 1.05 and 1.20 , all $p<0.05)$ and \\
\hline & & sector and for & & physical functioning (odds ratio $=$ \\
\hline & & patients referred by & & 0.81 (inpatient care) and 1.32 \\
\hline & & hospital physicians & & (outpatient), both $p<0.05$ ). The \\
\hline & & in the secondary & & survival time from referral to \\
\hline & & healthcare sector. & & specialized palliative care was on \\
\hline & & & & average longer for patients \\
\hline & & & & included in the study. The mean \\
\hline & & & & $\begin{array}{l}\text { number of symptoms/ problems were } \\
\text { very similar for patients referred by } \\
\text { the general practitioner and hospital } \\
\text { physicians. The difference between } \\
\text { patients referred by the general } \\
\text { practitioner and the hospital physician } \\
\text { did not seem to be clinically relevant } \\
\text { for any of the symptoms/problems or } \\
\text { overall QOL. }\end{array}$ \\
\hline
\end{tabular}

within 3 months of advanced cancer diagnosis for patients with median survival of 1 year or less, and progressive disease despite second-line therapy. Consensus was also reached on 36 minor criteria for specialist palliative-care referral.

\section{Outcomes}

Of the eight studies that explored the outcomes of $\mathrm{PC}$ in patients with cancer, two randomized controlled trials [28, 38] evaluated the benefit of early versus delayed PC referral on patient reported outcomes including quality of life (QOL), symptom impact, mood, survival and resource use. In the study of 151 patients with newly diagnosed metastatic non-small cell lung cancer, patients assigned to early PC had a better quality of life than did patients assigned to standard care [28]. In addition, even though there were fewer patients in the early PC group than in the standard care group that received aggressive end-of-life care (33\% vs. $54 \%, \mathrm{P}=0.05)$, median survival was longer among patients receiving early palliative care (11.6 months vs. 8.9 months, $\mathrm{P}=0.02$ ). Conversely, in another study comparing the effect of early versus delayed PC referral in 207 patients with advanced cancer, patient-reported outcomes (quality of life, symptom impact, mood, 1year survival), and resource use were not significantly different between patients with early referral than those with delayed referral [38]. However, the 1-year survival rate after study enrollment was improved in the early group (63\%) as compared with the delayed group (48\%; $\mathrm{P}=0.038$ ). Relative rates of resource use in early and delayed decedents were similar for hospital days $(0.73 ; 95 \% \mathrm{CI}, 0.41$ to $1.27 ; \mathrm{p}=.26)$, intensive care unit days $(0.68 ; 95 \% \mathrm{CI}, 0.23$ to $2.02 ; \mathrm{p}=.49)$, 
emergency room visits $(0.73 ; 95 \% \mathrm{CI}, 0.45$ to 1.19 ; $p=.21)$, chemotherapy in last 14 days $(1.57 ; 95 \% \mathrm{CI}$, 0.37 to $6.7 ; p=.27$, and home death $(27[54 \%] \vee 28$ $[47 \%] ; p=.60)$.

Three studies [24, 25, 29] evaluated the implementation of standardized criteria or triggers for palliative care (PC) consultation on the inpatient service for patients with solid tumors, advanced cancer, and its impact on the quality of cancer care. In patients with solid tumors, when standardized criteria for PC consultation were used, PC consultations doubled from 19 of 48 (39\%) to 52 of 65 (80\%), $\mathrm{P}<.001 ; 30$-day readmissions declined from 17 of 48 (35\%) to 13 of 65 (18\%), $\mathrm{P}=.04$; hospice referrals increased from seven of 48 (14\%) to 17 of $65(26 \%), P=.03$; and receipt of chemotherapy after discharge decreased from 21 of 48 (44\%) to 12 of 65 (18\%), P = .03 [25]. In patients with advanced cancer, Rocque et al. (2015) also noted that triggered PC consultation significantly improved patients' prognostic awareness of their cancer from $65 \%$ to $94 \%$, enhanced the communication between the patient and PC provider, and was viewed favorably by $74 \%$ of the oncologists [24]. Similarly, using the NCCN guidelines' criteria as a trigger for $\mathrm{PC}$ referral resulted in a significant increase in patients' access to PC service, and PC referral also appeared to occur earlier in the course of the disease as a result $[35,36]$. However, triggered PC consultation had minimal impact on hospice utilization, cost of care, survival, patient-reported symptoms, and patient satisfaction [23]. In addition, using the standardized criteria for automatic PC consultation did not significantly change length of stay ( $P=0.15)$ or use of the intensive care unit $(\mathrm{P}=0.11)$ [25], or hospital costs [27].

\section{Heart failure}

A total of 292,699 patients were included in the 14 studies of HF and PC (Table 4). Eight studies were retrospective, and six were prospective, with two of the included studies evaluating different data from the same randomized controlled trial of PC intervention. Eight studies looked at referral criteria only, five studies evaluated outcomes only, and one study evaluated both referral criteria and outcomes.

\section{Referral criteria}

The nine studies that assessed potential referral criteria for PC in patients with HF looked at various factors. Harding et al. (2009) compared characteristics of 28 admitted patients with HF between those who were appropriate for PC referral and those who were not. Patients with HF appropriate for PC referral had more previous admissions, had more multi-professional inpatient staff evaluating them, and were more likely to have a do-not- resuscitate order [43]. Other studies examined the accuracy of tools for predicting survival in HF patients, which could help guide goals-of-care discussion and PC referral. James et al. (2010) retrospectively applied the Seattle Heart Failure Model (SHFM) [44], which predicts lifespan using clinical, medication, laboratory, and intervention data, in patients admitted with HF to evaluate the accuracy of this model and its potential to identify patients who would benefit most from PC referral. The authors concluded that post-intervention SHFM scores could help identify patients for PC referral [45]. In another study, Ng Fat Hing et al. (2018) evaluated the use of SHFM to predict survival and guide when referral to PC should take place [46]. The authors found that SHFM captured the majority of patients who would have died within 1 year (95.3\%). However, the SHFM underestimated survival in the highest-risk patients, resulting in only $27 \%$ of this patient group being referred at an appropriate time. The study concluded that since the SHFM underestimates survival, many patients would be referred to PC too early, resulting in PC resources being expended unnecessarily. Avula et al. (2020) lso used the SHFM to predict mortality; in addition, the authors used the Placement Resource Indicator for Systems Management (PRISM) score, which is not specific to a disease [47]. The use of PRISM and a modified SHFM in combination significantly improved the ability to predict 1year mortality in HF patients compared with either model used alone.

Ezekowitz et al. (2011) prospectively evaluated 105 patients in outpatient HF clinics with two validated PC questionnaires (ESAS [41] and Palliative Performance Scale [48]) and two validated HF assessments (NYHA functional class [5] and Kansas City Cardiomyopathy Questionnaire [KCCQ] $[49,50])$ and found significant correlation between the PC and HF assessments ( $\mathrm{P}<$ 0.0001 for each PC assessment compared with NYHA class and compared with the KCCQ). The authors proposed that since the ESAS and Palliative Performance Scale showed good correlation with traditional HF scores, they could be useful in assessing HF patients for PC referral [51]. In a retrospective single-center study of all patients admitted for HF between 2005 and 2010, Greener et al. (2014) found that $6.2 \%$ were referred to $\mathrm{PC}$, and multivariable logistic regression analysis found several predictors of PC referral, including previous HFrelated hospitalizations, admission to the intensive care unit, older age, married status, and higher severity of illness. The authors speculated that being married was a predictor for PC referral because PC services provide resources not only for the patient but also for family members and caretakers [52]. Campbell et al. (2018) performed a prospective observational study of 272 patients and found that those needing a PC specialist were 
Table 4 Palliative/Supportive Care in Patients with Heart Failure

\begin{tabular}{lll}
\hline Study & Population & Aims \\
\hline Harding & 365 adult HF inpatients in & 1) To measure point \\
et al. & tertiary teaching hospitals & prevalence of inpatients \\
(2009) & in the UK & appropriate for PC \\
& & 2) To identify patient \\
& characteristics associated with \\
& PC appropriateness to inform \\
& referral criteria \\
& 3) To propose evidence-based \\
& clinical referral criteria
\end{tabular}

\section{Design}

Cross-sectional design, identifying chronic HF as a reason for current admission, using NYHA stage 3/4 classification, cross- referenced with existing echocardiogram data clinical referral criteria
James

214 patients with a

et al. discharge diagnosis of HF
To determine if SHFM can identify HF inpatients who would benefit from PC referrals
Cohort, retrospective and prospective Medical records

Retrospective, chart review

$\begin{array}{lll}\mathrm{Ng} \text { Fat } & 612 \text { patients with advanced } & \text { To use the SHFM as a } \\ \text { Hing et al. } & \text { NYHA HF and left } & \text { prediction of 1- year }\end{array}$

(2018) ventricular ejection fraction $\leq 40 \%$ decision-making
Avula

et al.

(2020)

Ezekowitz 105 patients $($ mean age $=$ et al. (2011)
689 patients with HF 65 years, $76 \%$ male, mean ejection fraction $=28 \%$ ) followed up in outpatient HF clinics
To assess the utility of PC questionnaires (NYHA, PPS, ESAS, and $\mathrm{KCCQ}$ ) in patients with $\mathrm{HF}$

\section{Key Findings}

Proposed criteria for $\mathrm{PC}$ referral for patients with chronic HF:

1. Symptomatic (e.g. breathless at rest or on minimal exertion) despite optimal treatment

2. On optimal therapy but with continuing or deteriorating physical or psychological symptoms 3. HF patients when hospital admission may not be the best/ only/preferred option, or for whom PC (hospice, day care, hospital inpatient or community care) may be of benefit, either immediately or in the future

4. Where the family or carer(s) would benefit from support, either immediately or in the future (including bereavement)

5. Where patient has had 2 or more previous admissions for HFwithin the last 6 months

The SHFM13 is a Web-based tool that uses specific clinical and laboratory variables, HF medications, and devices the patient currently has or will receive as predictor variables. Clinical variables entered into the tool include age, sex, NYHA classification, ejection fraction, ischemic cardiomyopathy, QRS duration, systolic blood pressure, and devices such as pacemakers and intraventricular conduction devices. $63 \%$ of HF patients with life expectancy $\leq 1.5$ years would have received timely $\mathrm{PC}$

consultation had the SHFM been used as a screening tool.

SHFM showed good discrimination for outcomes including 1-year event-free survival from death, heart transplant, and ventricular assist device implant among low- to moderate-risk patients but underestimated events in high-risk patients.

The discriminatory ability of modified SHFM was similar to that of the PRISM score, but the models in combination significantly improved the ability to predict 1-year mortality $(P=$ 0.002).

Cohort, prospective

The PPS and ESAS were each correlated to the NYHA class $(\mathrm{P}<$ 0.0001 for both) and the KCCQ score (PPS: R2 = 0.57; ESAS: R2 = -0.72 ; both $P<0.0001$ ). 33 patients died (10 patients) or were hospitalized (26 patients) for more than 1 year. In addition to age and sex, a higher (worse) ESAS score trended toward significance $(P=$ 0.07 ) and a lower (worse) PPS was significant $(P=0.04)$ in predicting all- 
Table 4 Palliative/Supportive Care in Patients with Heart Failure (Continued)

Study Population Aims Design

\section{Greener 2647 patients with HF \\ et al. admissions who received \\ (2014) and did not receive PC} services
To identify individual-level pre- Chart review, retrospective dictors of palliative care referral for HF patients
Campbell 272 patients screened for et al. specialized PC needs (2018)
To develop a definition of specialized PC

needs and assess outcomes of those

who received specialized PC
Prospective, observational 
Table 4 Palliative/Supportive Care in Patients with Heart Failure (Continued)

\begin{tabular}{|c|c|c|c|c|}
\hline Study & Population & Aims & Design & Key Findings \\
\hline & and December & days, skilled & & from $19 \%$ to nearly $40 \%$ of \\
\hline & 31,2007 & nursing facility & & patients $(P<0.001)$. Unadjusted \\
\hline & & stays, home health, & & mean costs to Medicare per \\
\hline & & hospice, durable & & patient rose $26 \%$ from $\$ 28,766$ to \\
\hline & & medical & & $\$ 36,216(P<0.001)$. After \\
\hline & & equipment, & & adjustment for age, sex, race, \\
\hline & & outpatient & & comorbid conditions, and \\
\hline & & physician visits, and & & geographic region, costs increased \\
\hline & & cardiac procedures. & & by $11 \%$ (cost ratio, $1.11 ; 95 \% \mathrm{Cl}$, \\
\hline & & & & 1.10-1.13). Increasing age was \\
\hline & & & & strongly and independently \\
\hline & & & & associated with lower costs. Renal \\
\hline & & & & disease, chronic obstructive \\
\hline & & & & pulmonary disease, and black race \\
\hline & & & & were independent predictors of \\
\hline & & & & higher costs. \\
\hline $\begin{array}{l}\text { Kheirbek } \\
\text { et }\end{array}$ & 179 hospice- & To examine the & Chart review, & 30-day all-cause readmission rate \\
\hline \multirow[t]{6}{*}{ al. (2015) } & referred patients & association of & retrospective & was $5 \%$ in the hospice-referred \\
\hline & matched with & discharge hospice & & group and $41 \%$ in the hospice- \\
\hline & 179 hospice- & referral with 30 day & & eligible group, corresponding to \\
\hline & eligible patients & all cause & & an HR of $0.12(95 \% \mathrm{Cl}, 0.06-0.24)$ \\
\hline & & & & for hospice referral. Hospice- \\
\hline & & $\begin{array}{l}\text { readmission in } \\
\text { decompensated HF }\end{array}$ & & $\begin{array}{l}\text { referred patients were admitted } \\
\text { later. } 30 \text {-day mortality was higher in } \\
\text { the hospice-referred group ( } 43 \% \text { ver- } \\
\text { sus } 27 \% \text { ) with an HR of } 1.86 \text { ( } 95 \% \mathrm{Cl} \text {, } \\
1.30-2.67) \text {. However, } \\
\text { among patients who were alive at } \\
30 \text { days, all-cause readmission oc- } \\
\text { curred in } 8 \% \text { of the hospice- referred } \\
\text { group versus } 39 \% \text { of the hospice- } \\
\text { eligible group (HR = } 0.17 \text {; } \\
95 \% \mathrm{Cl}, 0.08-0.36) \text {. }\end{array}$ \\
\hline $\begin{array}{l}\text { Rogers } \\
\text { et al. } \\
(2017)\end{array}$ & $\begin{array}{l}150 \text { patients randomized to } \\
\text { usual care versus PC } \\
\text { intervention }\end{array}$ & $\begin{array}{l}\text { To assess for quality-of-life out- } \\
\text { comes in patients receiving } \\
\text { usual care versus usual care } \\
\text { and PC intervention }\end{array}$ & Prospective, randomized & $\begin{array}{l}\text { Patients with PCintervention had } \\
\text { significant improvements in KCCQ } \\
\text { and FACIT-Pal scores at } 6 \text { months } \\
\text { (KCCQ difference: } 9.49 \text { points; } 95 \% \\
\text { Cl, 0.94-18.05; } P=0.030 ; \\
\text { FACIT-Pal difference: } 11.77 \text { points; } \\
95 \% \text { Cl, } 0.84-22.71 ; P=0.035 \text { ). } \\
\text { Depression also improved in the PC } \\
\text { intervention group (HADS- } \\
\text { depression difference: }-1.83 ; P= \\
\text { 0.048). Randomization did not affect } \\
\text { re-hospitalization or } \\
\text { mortality. }\end{array}$ \\
\hline $\begin{array}{l}\text { Truby } \\
\text { et al. } \\
\text { (2020) }\end{array}$ & 150 patients with HF & $\begin{array}{l}\text { Secondary analysis of trial by } \\
\text { Rogers et al. to compare } \\
\text { quality of life between men } \\
\text { and women }\end{array}$ & $\begin{array}{l}\text { Randomized controlled trial, } \\
\text { alternative outcome analysis }\end{array}$ & $\begin{array}{l}\text { Women had lower KCCQ scores } \\
(24.5 \text { versus } 36.2, P=0.04) \text {, but there } \\
\text { was no significant difference in the } \\
\text { FACIT-Pal scale ( } 115.7 \text { versus } 120.3 \text {, } \\
P=0.27) \text {. After referral to PC, men } \\
\text { had significant improvement in } \\
\text { KCCQ scores at } 6 \text { months, whereas } \\
\text { women did not }\end{array}$ \\
\hline
\end{tabular}


Table 4 Palliative/Supportive Care in Patients with Heart Failure (Continued)

\begin{tabular}{|c|c|c|c|c|}
\hline Study & Population & Aims & Design & Key Findings \\
\hline & & & & $(P=0.047$ versus $P=0.39)$ \\
\hline $\begin{array}{l}\text { Liu et al. } \\
\text { (2020) }\end{array}$ & $\begin{array}{l}57,272 \text { patients with } \\
\text { primary hospital encounter } \\
\text { diagnosis of HF or cancer } \\
\text { receiving PC consultation }\end{array}$ & $\begin{array}{l}\text { To evaluate outcomes of PC } \\
\text { consultations for hospitalized } \\
\text { patients with HF and cancer }\end{array}$ & $\begin{array}{l}\text { Retrospective, Palliative Care Quality } \\
\text { Network data set (nationwide } \\
\text { collaborative of interdisciplinary PC } \\
\text { teams) }\end{array}$ & $\begin{array}{l}\text { Patients with HF were older ( } 75.3 \\
\text { versus } 65.2 \text { years), had lower } \\
\text { Palliative Performance Scale scores } \\
(35.6 \% \text { versus } 42.4 \%) \text {, and were } \\
\text { more likely to be in a critical care } \\
\text { unit ( } 35.3 \% \text { versus } 12.5 \% \text { ) or } \\
\text { telemetry or step-down unit ( } 35.2 \% \\
\text { versus } 19.2 \% \text { ) compared with pa- } \\
\text { tients with cancer. Patients with HF } \\
\text { had more improvement in symp- } \\
\text { toms of dyspnea (odds ratio, } \\
2.17 \text { ) after PC referral compared with } \\
\text { patients with cancer. }\end{array}$ \\
\hline
\end{tabular}

HF heart failure; PC palliative care; NYHA New York Heart Association class; SHFM Seattle Heart Failure Model; PRISM Placement Resource Indicator for Systems Management; PPS Palliative Performance Scale; ESAS Edmonton Symptom Assessment System; KCCQ Kansas City Cardiomyopathy Questionnaire; NAT-PD-HF Needs Assessment Tool-Progressive Disease-Heart Failure; HR hazard ratio; FACIT-Pal Functional Assessment of Chronic Illness Therapy-Palliative Care; HADS Hospital Anxiety and Depression Scale; AKPS Australia-modified Karnofsky Performance Status

more likely to have been hospitalized for HF in the preceding 6 months and had a worse NYHA class, lower KCCQ score, and worse performance status assessed by a physician (Australia-modified Karnofsky Performance Status) [50]. However, in contrast to the previous studies presented, patients needing a PC specialist were younger $(\mathrm{P}=$ 0.076 ) and did not differ in number of comorbidities [53].

Kane et al. (2018) evaluated recruitment strategies for 372 patients with HF to undergo a PC needs assessment and ultimately compared 25 patients who completed the PC intervention. The authors found that using NYHA class as a criterion for referral to $\mathrm{PC}$ was problematic for two main reasons: (1) NYHA class can change owing to changes in volume status, so a proportion of patients with NYHA class II may have PC needs but momentarily appear too healthy for PC. (2) Assessment of NYHA class can be subjective, as seen in differences in application of NYHA class between sites included in the study. The authors recommended using indicators other than NYHA class for PC referral, as done in the 2016 European Society of Cardiology definition of HF [54]. Finally, Roch et al. (2020) evaluated an integrated PC outcome scale, which identified relevant symptoms for PC referral in $75 \%$ of patients and was determined by a vast majority of patients (95\%) to be an easy tool to understand. The study highlighted the importance of using tools accepted by both the patients and the providers when assessing PC referral [55].

\section{Outcomes}

A total of 287,595 patients were included in the six studies evaluating outcomes after PC referral. In a retrospective study of resource use near the end of life among 229,543 Medicare beneficiaries with HF, Unroe et al. (2011) found that hospice referral increased from $19 \%$ to almost $40 \%$ from 2000 to 2007 however, costs remained elevated, and use of other services such as inpatient hospitalization and echocardiograms did not decrease. Many patients had short hospice stays, with 37\% having stays less than 7 days, and the authors surmised that this short duration may have prevented patients and families from receiving the full benefit of hospice services, owing to the late referral [56]. Kheirbek et al. (2015) matched 179 hospice-referred patients with propensity-matched hospice-eligible patients and found that readmission rates were lower for the hospicereferred patients up to 6 months after discharge, including 30-day readmission. However, one possible explanation for the lower re-admission rate was the fact that over $40 \%$ of patients in the hospice-referred group died in the first 30 days after discharge, suggesting, again as the aforementioned study also stated, that PC referral occurred too late [57].

In the only randomized trial of PC intervention in HF patients, the primary endpoint for 150 patients was quality-of-life change at 6 months as assessed by the KCCQ and Functional Assessment of Chronic Illness Therapy-Palliative Care scale (FACIT-Pal) [58]. Patients with PC referral had statistically significant improvements in quality of life (KCCQ: $\mathrm{P}=0.030$, FACIT-Pal: $\mathrm{P}$ $=0.035$ ) compared with those with usual care; however, mortality was not affected and, as in other studies in our analysis, re-hospitalization was not affected [59]. A secondary analysis of the same trial evaluated differences in quality of life between men and women and found that men had significant improvement in KCCQ scores at 6 months, whereas women did not $(\mathrm{P}=0.047$ versus $\mathrm{P}=$ 0.39). Campbell et al. (2018), in addition to assessing predictors of needing specialist $\mathrm{PC}$, also prospectively evaluated outcomes of patients with HF. Only $24 \%$ of patients meeting criteria for needing specialist PC actually received PC. The patients meeting these criteria had 
significantly fewer days alive out of the hospital ( $\mathrm{P}<$ 0.001) compared with patients not meeting the criteria, but declines in quality of life were similar between groups, as assessed by ESAS and KCCQ scores [53].

\section{Discussion}

Cardio-oncology is already a multidisciplinary specialty with unique considerations for patient care when cancer coexists with cardiovascular disease, including HF. The added complexities of PC needs make this patient group a complicated one to treat. Many studies have evaluated PC in patients with cancer or HF, but a dearth of evidence exists regarding patients with both. This systematic review reveals areas of overlap and potential improvement for identifying PC referral criteria and assessing outcomes of $\mathrm{PC}$ intervention in these patients.

Cancer and HF share similarities in their patientreported symptoms, quality of life, symptom burden, social support needs, readmission rates, and mortality. Symptoms evaluated in questionnaires such as the ESAS for cancer and the KCCQ for HF commonly include fatigue and dyspnea assessments. This overlap may be a reason for the significant correlation found by Ezekowitz et al. (2011) between the ESAS and KCCQ assessments $(\mathrm{P}<0.0001)$. In addition to quantifying the severity of these symptoms, the questionnaires also quantify the degree to which the patient's quality of life is affected by the symptoms. Importantly, ESAS and KCCQ are patient-reported symptoms, as opposed to provider assessments, and patients are often more concerned with how they feel than with etiology or pathogenesis. Providers from both oncology and cardiology can address patient symptoms with $\mathrm{PC}$ intervention, regardless of whether symptoms are due to cancer or to HF. This multidisciplinary relevance is the strength of using patient- reported outcomes and there has been an increase in studies validating their use for various cancer and HF subtypes. Other symptoms that have been identified in both cancer and HF include anxiety, distress, delirium, and depression. Future studies of $\mathrm{PC}$ in patients with both cancer and HF should include quantification of all of these symptoms and their impact on quality of life.

One often-overlooked strength of PC intervention is the social support for caregivers in addition to the patient. The assessment of caregiver needs was addressed more in the included studies of cancer, while only one of the HF studies assessed this need. This difference may be due to the higher number of citations for PC with cancer compared to citations for PC with HF. Another possible explanation is the understanding and impression of a cancer diagnosis on patients and their families, compared with that of a diagnosis of HF. Many patients and family members associate cancer with a high risk of death; however, HF has worse mortality than many cancers but does not have the same stigma of death. Another factor is the predictability and duration of cancer treatment. Family members can plan for expected declines after chemotherapy or radiation and allocate the time needed to care for the patient. Therefore, increased use of caregiver-needs assessments are needed in the evaluation of patients with HF for PC.

With the increasing incidence of cardiotoxicity from anticancer agents that can result in HF, a collaboration between oncology and cardiology is paramount for the integration of $\mathrm{PC}$ to manage the complex issues in cardio-oncology patients. Although early referral to PC has been shown to improve outcomes, yet, PC referrals remain delayed because of a lack of criteria on who should be referred or the optimal timing for referral. To facilitate the incorporation of $\mathrm{PC}$ in the care of patients with cancer and HF, a set of criteria that address both cancer and HF are necessary. Table 5 shows a list of the referral criteria important for PC intervention in patients with cancer and patients with HF and identifies areas where there is overlap between cancer and HF. The next step would be to conduct a Delphi study on a combination of these proposed criteria to develop a consensus among the cardio-oncology experts on a list of criteria for PC referral for patients with cancer and HF. These criteria, if validated, could provide guidance for identification of patients suitable for referral to $\mathrm{PC}$, and could help streamline and standardize clinical practice, research and health care resources for this increasing number of patients.

Common outcome measures between PC intervention for HF and cancer include quality-of-life assessments through patient-reported outcomes, readmission rates, and mortality. As observed in the use of symptom and quality-of-life questionnaires for referral to $\mathrm{PC}$, there is overlap between cancer and HF patients in the use of these assessments as outcomes. Also, in both HF and cancer, readmission rates and mortality are used as significant outcomes to evaluate the efficacy of PC intervention. Mortality is a difficult measure for assessing PC efficacy, as aggressive life-saving measures will often not be pursued after PC referral, a choice that may contribute to early mortality. Furthermore, as highlighted in studies from this review, if PC referral occurs too late, the full benefit of PC services is not realized, as patients in one study passed away for an average of 7 days after referral. The outcomes of PC are thus tied with the timing of referral. Furthermore, the symptom assessment tools have limitations in their prediction of lifespan often overestimating or underestimating this important factor. Therefore, part of optimizing outcomes is assessing the time-based criteria for referral noted in Table 5. Further research is needed to improve individual lifespan prediction after a diagnosis of cancer and HF, which will then 
Table 5 Proposed Referral Criteria for PC for Patients with Cancer and Heart Failure

\begin{tabular}{|c|c|c|c|}
\hline \multirow[t]{2}{*}{ Criteria for referral } & & \multicolumn{2}{|c|}{$\begin{array}{l}\text { Used in patients } \\
\text { with }\end{array}$} \\
\hline & & Cancer & $\begin{array}{l}\text { Heart } \\
\text { failure }\end{array}$ \\
\hline \multirow[t]{27}{*}{ Need-based criteria } & Anxiety (severe) & $(H)$ & $\mathrm{Ng}$ \\
\hline & Assistance with decision making or care planning & $(\mathrm{H})$ & \\
\hline & Brain or leptomeningeal metastases & $(\mathrm{H}, \mathrm{C})$ & \\
\hline & Caregiving needs (family, caregiver limitations) & $(G, G L, N, S)$ & $\mathrm{Ha}$ \\
\hline & Cognitive impairment & $(\mathrm{GL})$ & \\
\hline & Communication barriers (language, physical) & $(\mathrm{GL})$ & \\
\hline & Deteriorating symptoms even with optimal therapy & & $(\mathrm{Ha})$ \\
\hline & Do-not-resuscitate order & & $\mathrm{Ha}$ \\
\hline & Dyspnea (severe) & $A, G$ & $E$ \\
\hline & Fatigue (severe) & $(S, G)$ & $(\mathrm{Ng})$ \\
\hline & Financial hardship & $(\mathrm{S}, \mathrm{G}, \mathrm{GL})$ & \\
\hline & Health system and informational needs & (S) & \\
\hline & History of drug or alcohol abuse & $(G, G L)$ & \\
\hline & Inadequate social support & $(\mathrm{G})$ & \\
\hline & Moderate to severe distress, delirium, depression & $\begin{array}{l}(\mathrm{A}, \mathrm{H}, \mathrm{G}, \mathrm{GL}, \\
\mathrm{N}, \\
\mathrm{S})\end{array}$ & $\begin{array}{l}(\mathrm{Gr}, \\
\mathrm{Ng})\end{array}$ \\
\hline & $\begin{array}{l}\text { Multiple adverse reactions to pain and symptom } \\
\text { management interventions }\end{array}$ & (G) & \\
\hline & Older age (> 75 years) & & $(G r)$ \\
\hline & Pain (including neuropathic) & $(A, G, G L, S, C)$ & \\
\hline & Patient request for referral & $(\mathrm{N}, \mathrm{H})$ & \\
\hline & Psychological distress/needs & $(G L, S)$ & \\
\hline & Psychiatric disorder & (G) & \\
\hline & Rapid escalation of opioid dose & $(\mathrm{GL})$ & \\
\hline & Request for hastened death & $(G, G L, H)$ & \\
\hline & Severe physical symptoms & $\begin{array}{l}(A, G, H, S, N, \\
C)\end{array}$ & $\mathrm{Ha}$ \\
\hline & Secondary diagnosis of Alzheimer disease & $(G r)$ & \\
\hline & Spiritual or existential crisis & $(G, S, H)$ & \\
\hline & Thoracentesis (multiple and recurrent episodes) & & $\mathrm{Gr}$ \\
\hline \multirow[t]{3}{*}{ Time-based criteria } & $\begin{array}{l}3 \text { months of advanced cancer diagnosis for patients with a median survival of } 1 \text { year or less ( } \leq 1.5 \\
\text { years expected life } \\
\text { span) }\end{array}$ & $(A, H)$ & $(J)$ \\
\hline & Higher severity of illness & & $(G r)$ \\
\hline & $\begin{array}{l}\text { Limited treatment options, especially in patients receiving phase I therapy or anticancer therapy with } \\
\text { a palliative intent }\end{array}$ & $(\mathrm{G})$ & $(\mathrm{Ng})$ \\
\hline \multirow[t]{4}{*}{ Illness trajectory criteria } & Health care utilization ( $>2$ hospital admissions within the last 6 months) & $(\mathrm{S}, \mathrm{A})$ & $\begin{array}{l}(\mathrm{Gr}, \\
\mathrm{Ha})\end{array}$ \\
\hline & Low KCCQ score & & $(G r)$ \\
\hline & Poor prognosis despite second-line therapy & $(H, N)$ & \\
\hline & Serious comorbid conditions (acute renal failure) & $(G L, N)$ & $(G r)$ \\
\hline $\begin{array}{l}\text { Worse performance status } \\
\text { (NYHA IV) }\end{array}$ & $\begin{array}{l}(\mathrm{Gr}, \\
\mathrm{Ha})^{2}\end{array}$ & & \\
\hline
\end{tabular}

Adelson = A, C = Caraceni, E = Ezekowitz, Glare = GL, Greener $=\mathrm{Gr}$, Grudzen = G, Ha = Harding, H = Hui, J

$=$ James, $\mathrm{N}=\mathrm{NCCN}, \mathrm{Ng}=\mathrm{Ng}$ Fat Hing, $\mathrm{S}=$ Sanders 
Citation Trends for Palliative Care and Cancer or Heart Failure

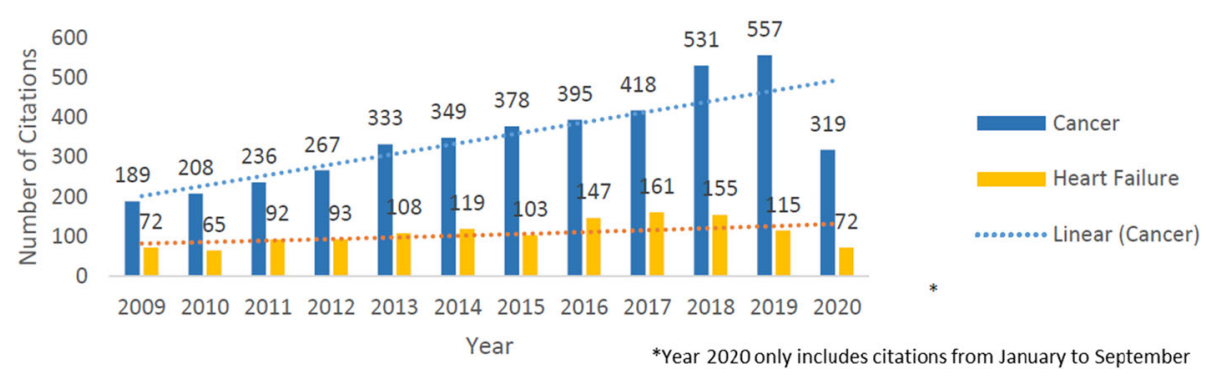

Fig. 2 Palliative care citations for cancer and heart failure

improve outcomes by enabling appropriate timing of PC referral.

Increasing awareness and recognition of $\mathrm{PC}$ as an important consideration for patients with cancer and $\mathrm{HF}$ is evident from the increased number of citations on this topic every year (Figure 2). Still, cancer citations outnumber those of HF 2 to 1 , and it is clear that more progress is needed to improve utilization of PC in patients with HF. At the time of this review, there is only one randomized controlled trial comparing the use of $\mathrm{PC}$ versus usual care in patients with HF. Even more understudied is the niche field of cardio-oncology involving PC referral in patients with both cancer and HF. More studies are needed to better delineate PC in this specialized patient population.

\section{Limitations}

The searches were limited to English only. Inclusion of articles in languages other than English may have broadened our results, but translation of these articles was not feasible. The limitations of this review were the lack of a quantitative statistical meta-analytic comparison of studies because of the heterogeneity of the study designs, participants, interventions, and reported outcome measures.

\section{Conclusion}

The complexities of the multiple issues confronting patients diagnosed with cancer and concurrent HF present challenges in decision-making regarding PC initiation. The multiple comorbidities of this population and the unpredictable illness trajectory of HF add to the complexity of prognostication, particularly with the potential for sudden cardiac death. This systematic literature review provides evidenced-based data to inform the development of criteria for PC referral for patients with cancer and concurrent HF, being mindful that referrals should not rely only on end-of-life or terminal stages. Integrating $\mathrm{PC}$ in cardio-oncology, particularly in the management of $\mathrm{HF}$ in patients with cancer, as early as at diagnosis, will enable patients, family members, and healthcare professionals to make informed decisions about various treatments and end-of-life care and provide an opportunity for patients to participate in the decisions about when and where they will spend their final days. Additional research is needed to develop and validate clinically useful criteria for PC referral to prospectively identify cancer patients with a concurrent diagnosis of HF patients who may most benefit from PC referral.

\section{Abbreviations}

ESAS: Edmonton Symptom Assessment System; FACIT-Pal: Functional Assessment of Chronic IIIness Therapy-Palliative Care; HF: heart failure; KCCQ: Kansas City Cardiomyopathy Questionnaire; NCCN: National

Comprehensive Cancer Network; NYHA: New York Heart Association;

PC: palliative care; SHFM: Seattle Heart Failure Model

\section{Acknowledgments}

The manuscript was edited by Sarah Bronson, ELS, Research Medical Library, The University of Texas MD Anderson Cancer Center.

Authors' contributions

The author(s) have read and approved the manuscript.

Funding

None

\section{Declaration}

Competing interests

none.

\section{Author details}

1Department of Nursing, The University of Texas MD Anderson Cancer Center, Houston, TX, USA. ${ }^{2}$ Department of Cardiology, The University of Texas MD Anderson Cancer Center, Houston, TX, USA. ${ }^{3}$ Department of Internal Medicine, Baylor College of Medicine, Houston, TX, USA. ${ }^{4}$ Research Medical Library, The University of Texas MD Anderson Cancer Center, Houston, TX, USA. ${ }^{5}$ Department of Palliative, Rehabilitation and Integrative Medicine, The University of Texas MD Anderson Cancer Center, Houston, TX, USA.

Received: 29 April 2021 Accepted: 9 August 2021

Published online: 23 September 2021

\section{References}

1. Xu, J., et al., Mortality in the United States, 2018. NCHS Data Brief, 2020 (355): p. 1-8.

2. World Health Organization (WHO). WHO definition of palliative care 2002; Available from: http://www.who.int/cancer/palliateive/definition/en/.

3. National Institute of Aging. [cited 2021 July 28, 2021]; Available from: https://www.nia.nih.gov/health/what-are-palliative-care-and-hospice-care. 
4. Lynn J, Teno JM, Phillips RS, Wu AW, Desbiens N, Harrold J, et al. Perceptions by family members of the dying experience of older and seriously ill patients. SUPPORT investigators. Study to understand prognoses and preferences for outcomes and risks of treatments. Ann Intern Med. 1997;126(2):97-106 https://doi.org/10.7326/0003-4819-126-2-19970115000001.

5. The Criteria Committee of the New York Heart Association. Nomenclature and Criteria for Diagnosis of Diseases of the Heart and Great Vessels. 9th ed. ed. 1994: Little, Brown \& Co.

6. Blinderman CD, Homel P, Billings JA, Portenoy RK, Tennstedt SL. Symptom distress and quality of life in patients with advanced congestive heart failure. J Pain Symptom Manag. 2008;35(6):594-603 https://doi.org/10.1016/j. jpainsymman.2007.06.007.

7. Bekelman DB, Rumsfeld JS, Havranek EP, Yamashita TE, Hutt E, Gottlieb SH, et al. Symptom burden, depression, and spiritual well-being: a comparison of heart failure and advanced cancer patients. J Gen Intern Med. 2009;24(5): 592-8 https://doi.org/10.1007/s11606-009-0931-y.

8. Bekelman DB, Havranek EP, Becker DM, Kutner JS, Peterson PN, Wittstein IS, et al. Symptoms, depression, and quality of life in patients with heart failure. J Card Fail. 2007;13(8):643-8 https://doi.org/10.1016/j.cardfail.2007.05.005.

9. Gadoud A, Kane E, Macleod U, Ansell P, Oliver S, Johnson M. Palliative care among heart failure patients in primary care: a comparison to cancer patients using English family practice data. PLoS One. 2014;9(11):e113188 https://doi.org/10.1371/journal.pone.0113188.

10. Setoguchi S, Glynn RJ, Stedman M, Flavell CM, Levin R, Stevenson LW. Hospice, opiates, and acute care service use among the elderly before death from heart failure or cancer. Am Heart J. 2010;160(1):139-44 https:// doi.org/10.1016/j.ahj.2010.03.038.

11. Bakitas M, MacMartin M, Trzepkowski K, Robert A, Jackson L, Brown JR, et al. Palliative care consultations for heart failure patients: how many, when, and why? J Card Fail. 2013;19(3):193-201 https://doi.org/10.1016/j.cardfail.2013. 01.011.

12. Institute of Medicine. Dying in America: Improving Quality and Honoring Individual Preferences Near the End of Life. 2015; Available from: https:// www.ncbi.nlm.nih.gov/books/NBK285681/.

13. Tulsky JA. Improving quality of care for serious illness: findings and recommendations of the Institute of Medicine report on dying in America. JAMA Intern Med. 2015;175(5):840-1 https://doi.org/10.1001/jama internmed.2014.8425.

14. Lindenfeld J, et al. HFSA 2010 comprehensive heart failure practice guideline. J Card Fail. 2010;16(6):e1-194 https://doi.org/10.1016/j.cardfail.201 0.04 .004 .

15. McMurray JJ, et al. ESC Guidelines for the diagnosis and treatment of acute and chronic heart failure 2012: The task force for the diagnosis and treatment of acute and chronic heart failure 2012 of the European Society of Cardiology. Developed in collaboration with the heart failure association (HFA) of the ESC. Eur Heart J. 2012;33(14):1787-847.

16. Feldman D, Pamboukian SV, Teuteberg JJ, Birks E, Lietz K, Moore SA, et al. The 2013 International Society for Heart and Lung Transplantation guidelines for mechanical circulatory support: executive summary. J Heart Lung Transplant. 2013;32(2):157-87 https://doi.org/10.1016/j.healun.2012.09. 013.

17. Yancy CW, Jessup M, Bozkurt B, Butler J, Casey DE Jr, Drazner MH, et al. 2013 ACCF/AHA guideline for the management of heart failure: executive summary: a report of the American College of Cardiology Foundation/ American Heart Association task force on practice guidelines. Circulation. 2013;128(16):1810-52 https://doi.org/10.1161/CIR.0b013e31829e8807.

18. Nishimura RA, Otto CM, Bonow RO, Carabello BA, Erwin JP 3rd, Guyton RA et al. 2014 AHA/ACC guideline for the Management of Patients with Valvular Heart Disease: a report of the American College of Cardiology/ American Heart Association task force on practice guidelines. Circulation. 2014;129(23):e521-643 https://doi.org/10.1161/CIR.0000000000000031.

19. Allen LA, Stevenson LW, Grady KL, Goldstein NE, Matlock DD, Arnold RM, et al. Decision making in advanced heart failure: a scientific statement from the American Heart Association. Circulation. 2012;125(15):1928-52 https:// doi.org/10.1161/CIR.0b013e31824f2173.

20. Fang JC, Ewald GA, Allen LA, Butler J, Westlake Canary CA, Colvin-Adams M, et al. Advanced (stage D) heart failure: a statement from the Heart Failure Society of America guidelines committee. J Card Fail. 2015;21(6):519-34 https://doi.org/10.1016/j.cardfail.2015.04.013.
21. Ferrell BR, Temel JS, Temin S, Alesi ER, Balboni TA, Basch EM, et al. Integration of palliative care into standard oncology care: American Society of Clinical Oncology clinical practice guideline update. J Clin Oncol. 2017; 35(1):96-112 https://doi.org/10.1200/JCO.2016.70.1474.

22. Dans M, Smith T, Back A, Baker JN, Bauman JR, Beck AC, et al. NCCN guidelines insights: palliative care, version 2. 2017. J Natl Compr Cancer Netw. 2017;15(8):989-97 https://doi.org/10.6004/jnccn.2017.0132.

23. Smith TJ, Temin S, Alesi ER, Abernethy AP, Balboni TA, Basch EM, et al. American Society of Clinical Oncology provisional clinical opinion: the integration of palliative care into standard oncology care. J Clin Oncol. 2012; 30(8):880-7 https://doi.org/10.1200/JCO.2011.38.5161.

24. Rocque GB, Campbell TC, Johnson SK, King J, Zander MR, Quale RM, et al. A quantitative study of triggered palliative care consultation for hospitalized patients with advanced Cancer the results of cohorts 1 and 2 were presented at the 2014 annual assembly of the American Academy of hospice and palliative medicine (AAHPM) and the hospice and palliative nurses association (HPNA). J Pain Symptom Manag. 2015;50(4):462-9 https:// doi.org/10.1016/j.jpainsymman.2015.04.022.

25. Adelson K, Paris J, Horton JR, Hernandez-Tellez L, Ricks D, Morrison RS, et al. Standardized criteria for palliative care consultation on a solid tumor oncology service reduces downstream health care use. J Oncol Pract. 2017; 13(5):e431-8 https://doi.org/10.1200/JOP.2016.016808.

26. Molin Y, Gallay C, Gautier J, Lardy-Cleaud A, Mayet R, Grach MC, et al. PALLIA10 , a screening tool to identify patients needing palliative care referral in comprehensive cancer centers: a prospective multicentric study (PREPA-10). Cancer Medicine. 2019;8(6):2950-61 https:/doi.org/10.1002/cam4.2118.

27. Brinkman-Stoppelenburg A, et al. The COMPASS study: a descriptive study on the characteristics of palliative care team consultation for cancer patients in hospitals. Eur J Cancer Care. 2019:e13172.

28. Temel JS, Greer JA, Muzikansky A, Gallagher ER, Admane S, Jackson VA, et al. Early palliative care for patients with metastatic non-small-cell lung cancer. N Engl J Med. 2010;363(8):733-42 https://doi.org/10.1056/NEJMoa1000678.

29. Hui D, Ross J, Park M, Dev R, Vidal M, Liu D, et al. Predicting survival in patients with advanced cancer in the last weeks of life: how accurate are prognostic models compared to clinicians' estimates? Palliat Med. 2020; 34(1):126-33 https://doi.org/10.1177/0269216319873261.

30. Caraceni A, Lo Dico S, Zecca E, Brunelli C, Bracchi P, Mariani L, et al. Outpatient palliative care and thoracic medical oncology: referral criteria and clinical care pathways. Lung Cancer. 2020;139:13-7 https://doi.org/10.1 016/j.lungcan.2019.10.003.

31. Gemmell R, Yousaf N, Droney J. "Triggers" for early palliative care referral in patients with cancer: a review of urgent unplanned admissions and outcomes. Support Care Cancer. 2020;28(7):3441-9 https://doi.org/10.1007/ s00520-019-05179-0

32. Hansen MB, Nylandsted LR, Petersen MA, Adsersen M, Rojas-Concha L, Groenvold M. Patient-reported symptoms and problems at admission to specialized palliative care improved survival prediction in 30,969 cancer patients: a nationwide register- based study. Palliat Med. 2020;34(6):795-805 https://doi.org/10.1177/0269216320908488.

33. Sanders SL, Bantum EO, Owen JE, Thornton AA, Stanton AL. Supportive care needs in patients with lung cancer. Psycho-Oncology. 2010;19(5):480-9 https://doi.org/10.1002/pon.1577.

34. Grudzen $C R$, Richardson LD, Morrison M, Cho E, Sean MR. Palliative care needs of seriously ill, older adults presenting to the emergency department. Acad Emerg Med. 2010;17(11):1253-7 https://doi.org/10.1111/j.1553-2712.2 010.00907.x.

35. Glare PA, Semple D, Stabler SM, Saltz LB. Palliative care in the outpatient oncology setting: evaluation of a practical set of referral criteria. J Oncol Pract. 2011;7(6):366-70 https://doi.org/10.1200/JOP.2011.000367.

36. Glare P, Plakovic K, Schloms A, Egan B, Epstein AS, Kelsen D, et al. Study using the NCCN guidelines for palliative care to screen patients for palliative care needs and referral to palliative care specialists. JNCCN. 2013;11(9):108796 https://doi.org/10.6004/jnccn.2013.0130.

37. Hui D, Mori M, Watanabe SM, Caraceni A, Strasser F, Saarto T, et al. Referral criteria for outpatient specialty palliative cancer care: an international consensus. Lancet Oncol. 2016;17(12):e552-9 https://doi.org/10.1016/S14 70-2045(16)30577-0.

38. Bakitas MA, Tosteson TD, Li Z, Lyons KD, Hull JG, Li Z, et al. Early versus delayed initiation of concurrent palliative oncology care: patient outcomes in the ENABLE III randomized controlled trial. J Clin Oncol. 2015:33(13): 1438-45 https://doi.org/10.1200/JCO.2014.58.6362. 
39. Scandrett KG, Reitschuler-Cross EB, Nelson L, Sanger JA, Feigon M, Boyd E, et al. Feasibility and effectiveness of the NEST13+ as a screening tool for advanced illness care needs. J Palliat Med. 2010;13(2):161-9 https://doi.org/1 0.1089/jpm.2009.0170.

40. Cohen SR, et al. Validity of the McGill quality of life questionnaire in the palliative care setting: a multi-Centre Canadian study demonstrating the importance of the existential domain. Palliat Med. 1997;11(1):3-20 https:// doi.org/10.1177/026921639701100102.

41. Bruera E, Kuehn N, Miller MJ, Selmser P, Macmillan K. The Edmonton symptom assessment system (ESAS): a simple method for the assessment of palliative care patients. J Palliat Care. 1991;7(2):6-9 https://doi.org/10.1177/ 082585979100700202.

42. Hui D, et al. Referral Criteria for Outpatient Palliative Cancer Care: A Systematic Review. Oncologist. 2016;21(7):895-901.

43. Harding R, Beynon T, Hodson F, Coady E, Kinirons M, Selman L, et al. Provision of palliative care for chronic heart failure inpatients: how much do we need? BMC Palliat Care. 2009;8(1):8 https://doi.org/10.1186/1472-684X-88.

44. Levy WC, et al. The Seattle Heart Failure Model: prediction of survival in heart failure. Circulation. 2006;113(11):1424-33.

45. James T, Offer M, Wilson M, Delyea A, Johnson D. Increasing palliative consults for heart failure inpatients using the Seattle heart failure model. J Hosp Palliat Nurs. 2010;12(5):273-81 https://doi.org/10.1097/NJH.0b013e31 $81 \mathrm{e} 0866 \mathrm{~b}$.

46. Ng Fat Hing $N$, et al. Utility of the Seattle Heart Failure Model for palliative care referral in advanced ambulatory heart failure. BMJ Support Palliat Care. 2018;06:06.

47. Avula S, LaFata M, Nabhan M, Allana A, Toprani B, Scheidel C, et al. Heart failure mortality prediction using PRISM score and development of a classification and regression tree model to refer patients for palliative care consultation. Int J Cardiol Heart Vasculature. 2020;26:100440 https://doi. org/10.1016/j.ijcha.2019.100440.

48. Campos S, Zhang L, Sinclair E, Tsao M, Barnes EA, Danjoux C, et al. The palliative performance scale: examining its inter-rater reliability in an outpatient palliative radiation oncology clinic. Support Care Cancer. 2009; 17(6):685-90 https://doi.org/10.1007/s00520-008-0524-z.

49. Green CP, Porter CB, Bresnahan DR, Spertus JA. Development and evaluation of the Kansas City cardiomyopathy questionnaire: a new health status measure for heart failure. J Am Coll Cardiol. 2000;35(5):1245-55.

50. Abernethy AP, Shelby-James T, Fazekas BS, Woods D, Currow DC. The Australia-modified Karnofsky Performance Status (AKPS) scale: a revised scale for contemporary palliative care clinical practice. BMC Palliat Care. 2005;4(7).

51. Ezekowitz JA, Thai V, Hodnefield TS, Sanderson L, Cujec B. The correlation of standard heart failure assessment and palliative care questionnaires in a multidisciplinary heart failure clinic. J Pain Symptom Manag. 2011;42(3):37987 https://doi.org/10.1016/j.jpainsymman.2010.11.013.

52. Greener DT, Quill T, Amir O, Szydlowski J, Gramling RE. Palliative care referral among patients hospitalized with advanced heart failure. J Palliat Med. 2014;17(10):1115-20 https://doi.org/10.1089/jpm.2013.0658.

53. Campbell RT, et al. Which patients with heart failure should receive specialist palliative care? Eur J Heart Fail. 2018;20(9):1338-47.

54. Kane PM, Murtagh FEM, Ryan KR, Brice M, Mahon NG, McAdam B, et al. Strategies to address the shortcomings of commonly used advanced chronic heart failure descriptors to improve recruitment in palliative care research: a parallel mixed- methods feasibility study. Palliat Med. 2018;32(2): 517-24 https://doi.org/10.1177/0269216317706426.

55. Roch C, et al. Utility of the integrated palliative care outcome scale (IPOS): a cross-sectional study in hospitalised patients with heart failure. Eur J Cardiovasc Nurs. 2020:1474515120919386.

56. Unroe KT, Greiner MA, Hernandez AF, Whellan DJ, Kaul P, Schulman KA, et al. Resource use in the last 6 months of life among medicare beneficiaries with heart failure, 2000-2007. Arch Intern Med. 2011;171(3):196-203 https:// doi.org/10.1001/archinternmed.2010.371.

57. Kheirbek RE, Fletcher RD, Bakitas MA, Fonarow GC, Parvataneni S, Bearden D, et al. Discharge hospice referral and lower 30-day all-cause readmission in Medicare beneficiaries hospitalized for heart failure. Circ Heart Fail. 2015; 8(4):733-40 https://doi.org/10.1161/CIRCHEARTFAILURE.115.002153.

58. Webster K, Cella D, Yost K. The Functional Assessment of Chronic Illness Therapy (FACIT) Measurement System: properties, applications, and interpretation. Health Qual Life Outcomes. 2003;1(79).
59. Rogers JG, Patel CB, Mentz RJ, Granger BB, Steinhauser KE, Fiuzat M, et al. Palliative Care in Heart Failure: the PAL-HF randomized, controlled clinical trial. J Am Coll Cardiol. 2017;70(3):331-41 https://doi.org/10.1016/j.jacc.2017. 05.030 .

\section{Publisher's Note}

Springer Nature remains neutral with regard to jurisdictional claims in published maps and institutional affiliations.
Ready to submit your research? Choose BMC and benefit from:

- fast, convenient online submission

- thorough peer review by experienced researchers in your field

- rapid publication on acceptance

- support for research data, including large and complex data types

- gold Open Access which fosters wider collaboration and increased citations

- maximum visibility for your research: over $100 \mathrm{M}$ website views per year

At BMC, research is always in progress.

Learn more biomedcentral.com/submissions 